\title{
Research on the Progressive Application Talents Training Mode of "Association $\rightarrow$ Competition $\rightarrow$ Entrepreneurship"___A Case Study of Internet of Things Major
}

\author{
Xiaojuan Zhang \\ Business College of Shanxi University, Taiyuan, Shanxi, 030031
}

Keywords: Internet of Things, Society, Entrepreneurship

\begin{abstract}
The Internet of Things (IoT) is an emerging industry with broad application prospects. It is urgent to train a large number of high-quality talents in colleges and universities. At present, many colleges and universities are planning to set up Internet-related professions from the perspective of their own development. This paper starts from the experience of the author's university in successfully applying for the Internet of Things engineering, and draws on the experience of relevant professional personnel to study the construction of the Internet of Things. It is proposed to combine the overall development characteristics of the school, study the Internet of Things technology system, formulate professional training objectives, and construct the Internet of China professional curriculum system structure, in order to promote the construction of the Internet of Things professionals, the construction of the curriculum system and the teaching practice.
\end{abstract}

\section{Introduction}

The Internet of Things is another revolutionary development in the information industry following computers, the Internet and mobile communications. The Internet of Things is officially listed as one of the strategic emerging industries that the country focuses on. The Internet of Things industry has the characteristics of long industrial chain and multiple industrial clusters. Its application scope covers almost all industries. With the increasing demand for IoT talents, universities have applied for new majors in the Internet of Things project. Our school is the first batch of institutions of higher learning with the right to grant a Bachelor of Science in Engineering. How to train undergraduates of the Internet of Things engineering, how to locate the Internet of Things engineering major, how to cultivate the innovation ability of students of the Internet of Things engineering, has become an urgent problem that needs to be solved urgently. At present, there is not a large number of graduates in the Internet of Things engineering profession. What basic skills and basic qualities should be possessed by undergraduate students of the Internet of Things project. The employment situation and employment industry are still not very clear. A few IoT graduates are also engaged in embedded systems development, software development and other fields. The professional training mode and professional positioning are still in the process of exploration. This topic intends to establish a talent training model suitable for our department after market research, exchanges and study with famous universities at home and abroad, combined with the actual teaching experience of our teaching and research section.

\section{Construction of talent training system}

The so-called applied talents are the main tasks of transforming scientific theories into technologies or programs for production, service and management of front-line operations, emphasizing the combination of learning and learning, learning and combining, and learning and creation. As a local undergraduate college, Changshu Institute of Technology has always been guided by social needs and aims to cultivate applied talents that serve the local economy. According to the economy of the Yangtze River Delta region in Suzhou and the actual situation of the school, the Internet of Things Engineering of Changshu Institute of Technology adheres to the road of talent cultivation of "school-enterprise cooperation" and cultivates the "discipline basis" for industries 
such as intelligent agriculture, intelligent logistics and smart home. Application-oriented talents that are solid, hands-on, and meet industry needs.

The training objective of the Internet of Things engineering professionals is to cultivate the comprehensive development of morality, intelligence, body and beauty. It has comprehensive characteristics such as thick foundation, wide caliber, strong ability and high quality. It has a sense of social responsibility and systematically masters the basic theory and physics of Internet of Things technology. Information system identification and perception, computer network theory and technology, and data analysis and processing methods, with information acquisition, storage, retrieval, analysis and processing capabilities, can play a leading role in the information field of computer, automation and communication, with an international perspective and competitive and innovative engineering and management talents.

\section{Construction of talent training mode}

In general, talent training can be divided into four types: college training, training institution training, corporate training, and self-study. Colleges and universities have obvious systemic advantages in personnel training, but the practical application is not the strength of colleges and universities. It is difficult to cultivate talents who have a solid theoretical foundation and master the practical application skills of the industry. The specific needs of enterprises to develop talents require a large number of engineering and technical personnel with rich practical experience. Therefore, as a talent supply university and a talent receiving enterprise, a talent cooperation training mode is established to give full play to their respective advantages to solve the current Internet of Things engineering. Applying the various problems of talent cultivation, the talent training end and the receiving end can reach the maximum match. The cultivation of school-enterprise cooperation talents is of great significance. First, colleges and universities can track industry changes, understand the specific needs of IoT engineering professionals, determine the positioning and goals of IoT engineering professionals, and make full use of the teachers and schools to solve the current shortage of teachers; Enterprises can recruit talents that meet their own development needs through school-enterprise cooperation. Third, students can master more practical application skills through school-enterprise cooperation and find satisfactory jobs. In the end, the school, the enterprise and the students achieved a win-win situation.

In order to meet the needs of IT application talents in Suzhou and even the Yangtze River Delta region, Changshu Institute of Technology, in conjunction with local governments, software parks, and well-known enterprises, has played its own advantages and functions, and has developed talents for school-enterprise cooperation. The talent training of the Internet of Things Engineering of Changshu Institute of Technology adopts the " $3+1$ " talent training mode based on the cooperation between schools and enterprises, that is, the students are jointly trained on the basis of integrating the superior resources of the school and the enterprise. The students learn the theory in the first three years. Knowledge, entered the corporate practice in the last year. The teaching below the dotted line in Figure 1 is completed in the school, and the teaching above the dotted line is completed in the enterprise. The quality development part of the teaching runs through the four school years, teachers can be flexible implementation according to the actual situation.

\section{The specific content of the school-enterprise cooperation talent training model}

Knowledge is the foundation of the formation of ability. The formation of students' professional ability is inseparable from the study of theoretical knowledge, work process knowledge and practical knowledge. To cultivate applied undergraduate talents, it is necessary to break through the traditional curriculum structure designed according to the discipline paradigm, break the curriculum model of "Public Basic Course + Professional Basic Course + Professional Course", and make bold integration, trade-off and innovation of the theoretical curriculum system to consolidate the formation of students' professional ability. The knowledge base required to enhance students' developmental stance. After many years of exploration, the teachers of the School of Computer 
Science and Engineering divided the curriculum teaching system into a quality foundation (a public curriculum prescribed by the school), a subject basis (a platform course required by the college), a professional foundation (a major course required for the major), and engineering technology ( Engineering and technical courses required by industry and industry) and vocational skills (vocational courses for occupations and enterprises). The School of Computer Science and Engineering's Internet of Things Engineering has signed a talent cooperation and training agreement with a number of companies. Therefore, the Department of Computer Science and Engineering, Internet of Things Engineering, on the one hand, in the course of the curriculum teaching system, with reference to the national Internet of Things and related professional teaching guidance group developed the Internet of Things engineering professional knowledge system and curriculum planning; In the course of the curriculum and adjustment of the professional direction, solicit the opinions of the cooperative enterprises, and combine the actual situation of the college and the enterprise to jointly formulate the theoretical teaching system and vocational skill teaching system of the Internet of Things engineering, the teaching plan and training standards of the relevant courses. Make teaching plans, curriculum and teaching content closely related to social practice to meet the needs of social development.

The “Three Environments" provide students with three practical environments: on-campus experiments, campus training, and corporate internships. The School of Computer Science and Engineering has established a provincial computer experiment teaching demonstration center construction point, college students innovation training center, Internet of Things and intelligent computing research center and other on-campus experimental training bases; established Changshu Southeast Development Zone, which is used by the park for investment and schools. Training bases, Hai'an Software Park Training Base, Kunshan Huaqiao Business City Training Base and other park-level training bases, as well as more than 30 enterprise practice bases such as Shanghai Ideal, Kunshan Jiepu, Jiangsu Net God. The “Three Environments” ensure the smooth progress of student training internships.

School-enterprise cooperation talent training can enable students to shorten the period of adaptation after entering the company in a part-time and half-reading manner, and provide a strong guarantee for the future development of students. At present, the School of Computer Science and Engineering cooperates with Shanghai Ideal, Jiangsu Internet God and other enterprises to carry out project training and teaching. Students are sent to enterprises for internships, so that students have accumulated certain work experience. The joint efforts of the School of Computer Science and Engineering and the enterprise enable students to adapt to the corporate environment and job requirements after graduation, so that they can sign up for the job smoothly. In recent years, under the influence of this employment mechanism, software engineering and network engineering students have signed more than $90 \%$. Since students have already contacted and mastered relevant knowledge and skills while they are at school, and have improved other aspects such as management ability, students can quickly adapt to and quickly enter the role of corporate employees after entering the job, laying a solid foundation for future personal development.

School-enterprise cooperation requires deep cooperation between schools and enterprises if they are to truly realize their advantages. The main energy of the enterprise will only be invested in its own survival and development. Therefore, in the process of cooperation, the school should not become a "hands-on shopkeeper" and push all tasks to the enterprise. The School of Computer Science and Engineering and the cooperative enterprises participate in the development of theoretical courses and practical courses. The School of Computer Science and Engineering is equipped with a team of teachers led by senior professional teachers for each cooperative enterprise. They are responsible for cooperation with enterprise development. Courses, including textbooks, training materials, teaching plans, outlines, and lesson plans. This method can not only enhance the enthusiasm of the two sides to participate in cooperation, but also improve the engineering practice ability of professional teachers, and can produce substantive cooperation results, which is of great significance for improving the quality of personnel training.

In order to ensure the smooth progress of school-enterprise cooperation projects, government 
representatives, school leaders, park leaders and business representatives jointly form a school-enterprise cooperation and coordination steering committee to comprehensively guide and coordinate school-enterprise cooperation related matters to promote long-term, mutually beneficial and efficient cooperation between schools and enterprises. According to the characteristics of teaching reform and professional direction, the School of Computer Science and Engineering employs IT enterprises, industry experts and school teachers to form a professional teaching steering committee and its working group to jointly discuss and clarify the training objectives of professional talents and determine the plan for professional teaching plans. And teaching content, provide information on talent demand, and timely adjust the curriculum teaching plan and training plan according to the needs of IT enterprises and industry, and evaluate the teaching effect.

\section{Conclusion}

The Internet of Things Engineering is a brand new major, and it has a strong practicality across a variety of professional categories. Can the talent training model of the School of Computer Science and Engineering train excellent IoT engineering professionals for local economic development? Continue to explore and improve, and test through practice.

\section{Acknowledgements}

Fund Project: Shanxi Education Science 13th Five-Year plan (GH-17099, GH-16182), Teaching reform and innovation projects in Universities in Shanxi (J2018237, J2018017).

\section{References}

[1] Zhu Linsheng, Wang Yage. Cooperative Education: Strategic Choice of Newly Established Undergraduate Colleges[J]. Heilongjiang Higher Education Research, 2011(12): 45-47.

[2] Fang Xuejun, Ma Tiecheng, Gu Xiumei, et al. Research and practice of application-based undergraduate training model reform[J]. Liaoning Education Research, 2008(12): 65-67

[3] Xu Xiaolong, Lu Weifeng, Yang Geng. Research on the training strategy of Internet of Things professionals [J]. Journal of Nanjing University of Posts and Telecommunications, 2012 (1).

[4] Kong Xiangfei. Thinking about the opening of the Internet of Things [J]. Teaching and Research of Shijiazhuang City Vocational College, 2013 (3).

[5] Mulberry. Research on the construction of the professional staff of the Internet of Things [J]. China Electric Power Education, 2013 (13).

[6] Gu Weijie, Wang Yunliang. Thoughts on the professional positioning of Internet of Things at different levels of education [J]. China Electric Power Education, 2011 (27). 